Cite this: Chem. Sci., 2014, 5, 1128

\title{
Lipophilic balance - a new design principle for transmembrane anion carriers $\uparrow$
}

\author{
Hennie Valkenier, ${ }^{a}$ Cally J. E. Haynes, ${ }^{b}$ Julie Herniman, ${ }^{\text {b }}$ Philip A. Gale ${ }^{\star b}$ \\ and Anthony P. Davis ${ }^{\star a}$ \\ Despite extensive interest in transmembrane anion carriers (anionophores), the factors that govern activity \\ are still only partly understood. Herein we report a study which identifies a new principle for anionophore \\ design, that of "lipophilic balance". A series of simple thioureas with identical molecular formulae has been \\ prepared and assayed for chloride/nitrate transport activity in synthetic vesicles. The molecules differ only in \\ the positioning of the phenylthiourea binding unit within an 11-carbon linear chain. They are shown to \\ possess very similar lipophilicities and anion affinities, while a test for leaching establishes that they \\ locate almost exclusively in the vesicle membranes. Notwithstanding their close similarities, activities \\ across the series show $>5$-fold variation, peaking when the phenylthiourea group is centrally located. \\ The results suggest that transport is favoured by a balanced array of lipophilic substituents, possibly \\ because this arrangement facilitates transfer of the complexed anion into the apolar membrane interior. \\ Received 25th October 2013 \\ Accepted 11th November 2013 \\ DOI: $10.1039 / c 3 s c 52962 b$ \\ www.rsc.org/chemicalscience
}

being Best disease, Bartter's syndrome and cystic fibrosis. ${ }^{3}$ In principle, anion transporters might be used to treat these conditions by replacing the missing activity, in an approach termed "channel replacement therapy". ${ }^{4}$

Anion transport may be achieved by a number of strategies including self-assembled channels, ${ }^{5}$ relay systems,${ }^{6}$ and mobile carriers. $^{7-24}$ For biological applications, carriers are probably favoured as they do not require cooperative action by several molecules and hence can function at low dose. Carriers may be positively charged, forming neutral complexes which can easily pass through membrane interiors, or may acquire positive charge through protonation. However lipophilic cations tend to be toxic, and protonatable molecules may also be capable of proton transport. Thus, for channel replacement therapy, the most promising approach is arguably the use of electroneutral anion carriers. Such molecules mirror the action of valinomycin, the well-studied electroneutral cation carrier, and may thus be termed "anti-valinomycins". ${ }^{1 f}$

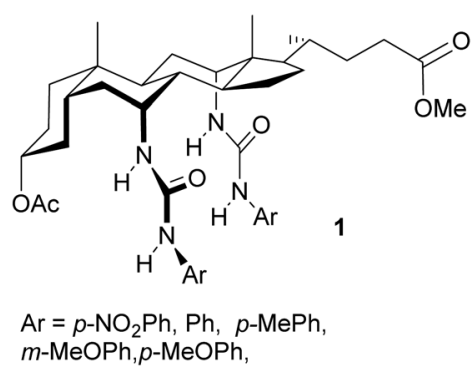

To serve as an anti-valinomycin, a molecule must be able to bind the target anion from water, without involving a countercation, and ferry it through the membrane interior. The
${ }^{a}$ School of Chemistry, University of Bristol, Cantock's Close, Bristol, BS8 1TS, UK. E-mail: anthony.davis@bristol.ac.uk

${ }^{b}$ Chemistry, University of Southampton, Southampton, SO17 1BJ, UK. E-mail: philip. gale@soton.ac.uk

$\dagger$ Electronic supplementary information (ESI) available: Synthesis and characterisation of the new transporter compounds 10c, $\mathbf{d}, \mathbf{f}-\mathbf{h}$; experimental and analysis details for ${ }^{1} \mathrm{H}$ NMR titrations; experimental details for measurement of chloride transport by the lucigenin assay, with additional fluorescence plots; experimental details of ion-selective electrode (ISE) measurements and Hill plots; details of lipophilicity assessments by reverse-phase HPLC. See DOI: 10.1039/c3sc52962b 
feasibility of this process was first demonstrated in 2003, when the "cholapod" bis-ureas 1 were shown to exchange chloride and nitrate across synthetic vesicle and natural cell membranes. ${ }^{7}$ Further work has shown that a variety of neutral molecules, some far less sophisticated than 1, can act as anion carriers. As illustrated in Fig. 1, examples include simple mono-ureas and -thioureas $2,^{8-11}$ (thio)ureidoindoles $3,^{9,10,15}$ squaramides $4,^{16}$ isophthalamides $5,{ }^{17,18}$ hydroxyamides $6,{ }^{19}$ diureido-benzenes $7^{20}$ and -decalins $8,{ }^{21}$ and a variety of cholapods $9 .{ }^{7,822}$ A number of principles governing anionophore effectiveness have emerged from this research. Firstly there is a connection (though somewhat loose) between anion binding strength and transport activity. The most powerful anionophores (e.g. 7-9) possess multiple hydrogen bond donor groups and, in closely-related structures, it is usually found that affinities correlate with transport rates. Secondly lipophilicity plays a key role, if only to ensure that the carrier is located in the membrane. . $^{11,12,15,23}$ Support for these generalisations was recently obtained from a QSAR study, which also suggested an inverse correlation between size and effectiveness. ${ }^{11}$ Finally, there is evidence that structures which encapsulate the anionic substrate may be favoured. ${ }^{24}$

While these guidelines are helpful, there are still many variations in anionophore performance that are difficult to explain. One example emerged from studies of diureido decalins 8. ${ }^{21}$ These carriers were prepared in three variants, with side-chain $\mathrm{R}=\mathrm{Me}$, Et and octyl. Interestingly, activities were found to increase quite substantially in this order. On one level this correlation between activity and lipophilicity might have been anticipated, as the octyl derivative is more reliably
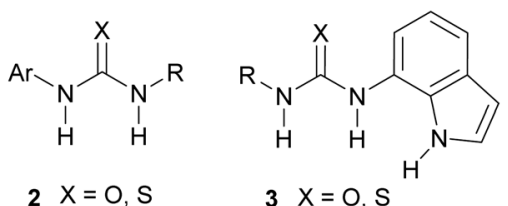

$3 \mathrm{X}=\mathrm{O}, \mathrm{S}$

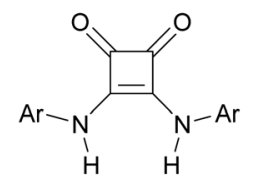

4<smiles>[R]NC(=O)c1cc(C(=O)NCP)c(O)cc1O</smiles><smiles>[R]C(=O)NCC(O)CO</smiles><smiles>[3H]NC(=O)Nc1ccccc1NC(=O)NC=[V]</smiles>

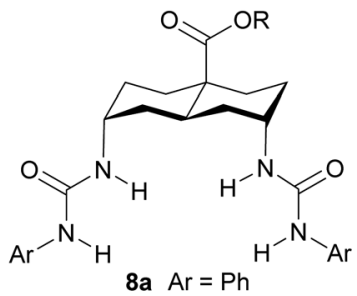
8b $\mathrm{Ar}=4-\mathrm{CF}_{3} \mathrm{Ph}$

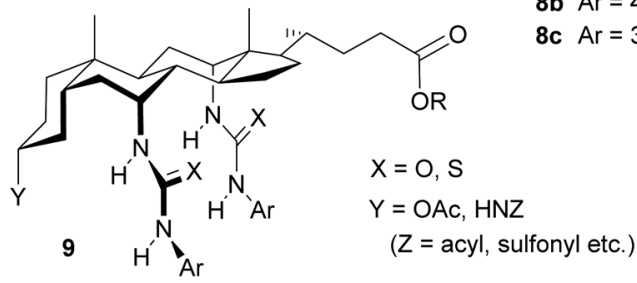

Fig. 1 Structures of electroneutral anion carriers. confined to the membrane (see above). However, in this case all variants were highly lipophilic. Even the Me derivatives were expected to locate exclusively in the membrane interior, and indeed were shown to do so. ${ }^{25}$ Lipophilicity might confer some benefit beyond partitioning. However in cholapods $\mathbf{9}$, a major lengthening of side-chain $\mathrm{R}$ (from $\mathrm{CH}_{3}$ to $\mathrm{C}_{20} \mathrm{H}_{41}$ ) yielded no improvement. ${ }^{8}$ This implied that, once the transporter is in the membrane, the effect of added hydrocarbon might not be straightforward. In particular it suggested that overall lipophilicity might be less important than achieving a particular distribution of lipophilic groups within the molecule.

Resolving such issues in the powerful but complex anionophores 8 and 9 would be difficult, so we turned to the simple thioureas $2(\mathrm{X}=\mathrm{S})$. These are easily varied and, though not especially active, show readily measurable chloride-nitrate exchange in synthetic vesicles. They have previously been used to show the effects of hydrogen bond donor strength and overall lipophilicity on anionophore activity. ${ }^{11}$ Here we report a study which focuses on variants in which both these factors are kept constant. The results suggest a new design principle for anion carriers, namely that the anion-binding site should be placed centrally within the scaffold, surrounded by a balanced array of lipophilic substituents.

\section{Results and discussion}

\section{Experiment design and procedures}

Our plan was to test a series of $N$-arylthioureas of general form 10, where $R_{1}$ and $R_{2}=H$ or alkyl. The hydrogen bond donor strength of these systems should be very similar, while the lipophilicities should vary according to the total number of carbon atoms in $\mathrm{R}_{1}+\mathrm{R}_{2}\left(C_{\text {total }}\right)$. By keeping this number constant, we could generate a series with almost identical binding strength and lipophilicity, and would thus be able to probe solely the effect of binding site position (Fig. 2a). To simplify interpretation of the transport data, we preferred to choose $R_{1}+R_{2}$ such that the transporters were confined to the membrane. In this case concentrations within the membrane could be known for certain, and the data could be guaranteed to reflect intrinsic transport ability. An initial study was thus required to determine $C_{\text {total }}$, as described below.

$$
\begin{aligned}
& \text { 10a } \mathrm{R}_{1}=\mathrm{H}, \quad \mathrm{R}_{2}=\text { hexyl } \\
& \text { 10b } \mathrm{R}_{1}=\text { ethyl, } \mathrm{R}_{2}=\text { hexyl } \\
& \text { 10c } \mathrm{R}_{1}=\mathrm{H}, \quad \mathrm{R}_{2}=\text { undecyl } \\
& \text { 10d } \mathrm{R}_{1}=\text { ethyl, } \mathrm{R}_{2}=\text { nonyl } \\
& \text { 10e } \mathrm{R}_{1}=\text { pentyl, } \mathrm{R}_{2}=\text { hexyl } \\
& \text { 10f } \mathrm{R}_{1}=\text { octyl, } \mathrm{R}_{2}=\text { propyl } \\
& \text { 10g } \mathrm{R}_{1}=\text { nonyl, } \mathrm{R}_{2}=\text { ethyl } \\
& \text { 10h } \mathrm{R}_{1}=\text { pentyl, } \mathrm{R}_{2}=\text { cyclohexyl }
\end{aligned}
$$

To measure transport effectiveness, we focused mainly on the "lucigenin method" (Fig. 2b). ${ }^{1 f, 22}$ Briefly, solutions of the 
(a)

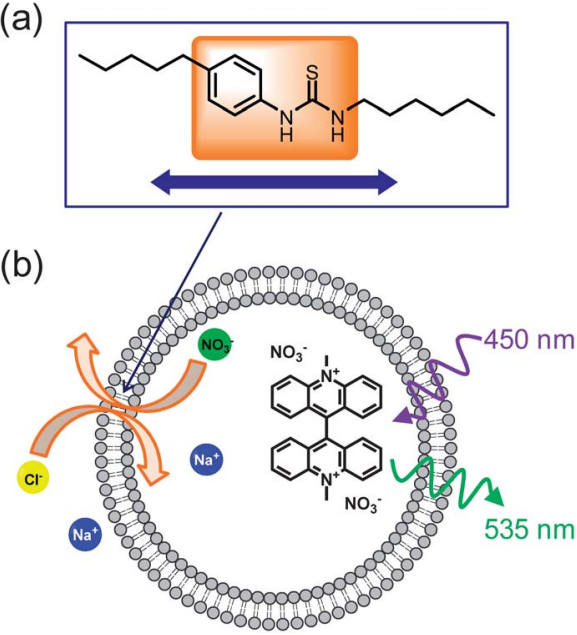

Fig. 2 Graphical summary of this study: (a) Transporter structures are varied such that the thiourea anion-binding group is moved systematically within a hydrocarbon chain of defined length. (b) Transport activities in synthetic vesicles are measured using the lucigenin assay. Transporter molecules promote exchange of $\mathrm{Cl}^{-}$for $\mathrm{NO}_{3}{ }^{-}$(via an antiport mechanism), detected through quenching of lucigenin fluorescence by incoming chloride.

lipids 1-palmitoyl-2-oleoyl-sn-glycero-3-phosphocholine (POPC) and cholesterol in chloroform $(7: 3$ ratio) were mixed with a solution of $\mathrm{N}$-arylthiourea transporter in methanol, so that the transporter to lipid ratio was $1: 250$. The organic solvents were removed and the pre-mixed transporter/lipid film was rehydrated with an aqueous solution of $0.8 \mathrm{mM}$ lucigenin and $225 \mathrm{mM}$ sodium nitrate. The vesicles were then extruded through a membrane with $200 \mathrm{~nm}$ pores and external lucigenin was removed by size exclusion chromatography. The vesicles were diluted with $225 \mathrm{mM}$ aqueous sodium nitrate solution to a final lipid concentration of $0.4 \mathrm{mM}$. Upon addition of $25 \mathrm{mM}$ sodium chloride to the bulk solution the $N$-arylthiourea started to exchange chloride for nitrate across the vesicle membrane (see Fig. 2b). Quenching of lucigenin fluorescence by incoming chloride caused a decay in fluorescence output, which was measured over time. The normalized and averaged fluorescence curves were analysed to obtain two quantitative measures of transport effectiveness. Fitting to a double-exponential decay function produced accurate reproductions of the curves, from which initial rates $I$ (changes in relative fluorescence, $F / F_{0}$ ) were calculated. Fitting to a single exponential decay allowed the effective half-lives $t_{1 / 2}$ to be estimated. ${ }^{8}$ Further details on the preparation of vesicles, transport measurements, and fitting of the data are given in the ESI. $\dagger$

To check for variations in the "constant" parameters, we also measured the binding strengths and lipophilicities of the thioureas. Binding constants $\left(K_{\mathrm{a}}\right)$ to $\mathrm{Bu}_{4} \mathrm{~N}^{+} \mathrm{Cl}^{-}$in $\mathrm{CDCl}_{3}$ were determined by ${ }^{1} \mathrm{H}$ NMR titration, while lipophilicities were assessed by reverse phase HPLC using a Kinetex C18 column and a gradient of $50 \%$ methanol in water to $100 \%$ methanol as mobile phase.

\section{Choice of $C_{\text {total }}$ leaching of thioureas from bilayer membranes}

As discussed above, the interpretation of this study would be more secure if the transporters were known to reside solely in the membranes, so that loadings could be accurately known. Accordingly, we performed a preliminary study on thioureas 10a, 10b, and 10e $\left(\mathrm{R}_{2}=\mathrm{C}_{6} \mathrm{H}_{13} ; \mathrm{R}_{1}=\mathrm{H}, \mathrm{C}_{2} \mathrm{H}_{5}, \mathrm{C}_{5} \mathrm{H}_{11} ; C_{\text {total }} 6,8\right.$ and 11 respectively). As expected, measured lipophilicities and transport efficiencies both increased in this order (Table 1, Fig. 3a), confirming the results of an earlier study involving these compounds. ${ }^{11}$

To check the distribution of these transporters between aqueous and lipid phases, we followed a previously reported procedure. ${ }^{21}$ Lucigenin-containing POPC/cholesterol vesicles were prepared with transporter present in the membrane as described before. However before testing for anion transport, the suspensions were diluted from $0.4 \mathrm{mM}$ lipid to $0.2 \mathrm{mM}$. A further assay was then performed after dilution to $0.1 \mathrm{mM}$. If the transporter is confined to the membrane the traces at different concentrations should be superimposable after taking account of the dilution by normalisation. As shown in Fig. 3b, this was true to a good approximation for 10e. However, if the transporter partitions to any extent into the aqueous phase, dilution of the suspension should reduce the concentration in the bilayers. The overall effectiveness therefore becomes

Table 1 Overview of the molecular properties, transport and binding data of compounds 10a-h

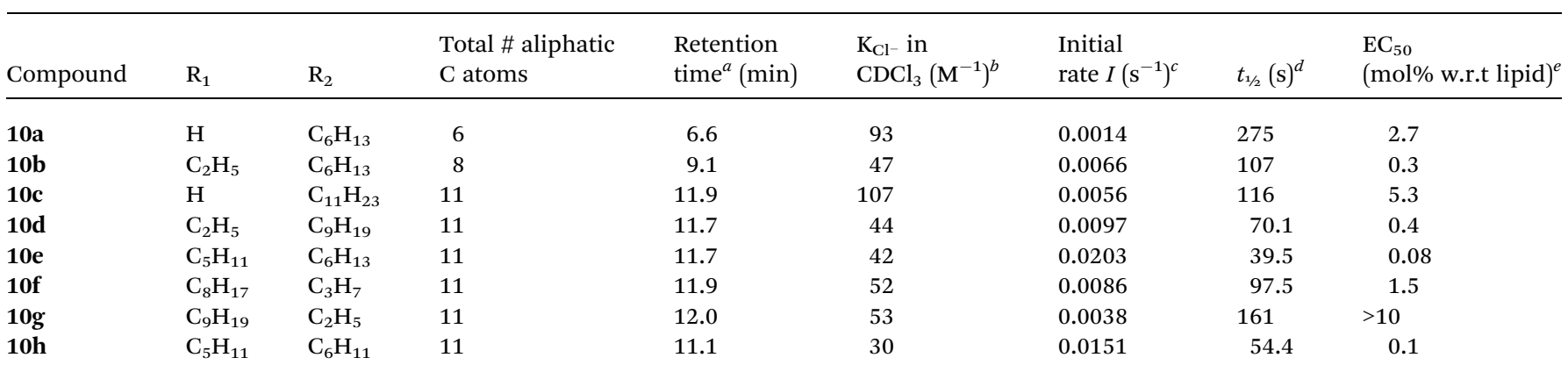

${ }^{a}$ Retention times on a reversed-phase HLPC, employed as an experimental measure of lipophilicity. ${ }^{b}$ Binding constants measured by ${ }^{1} \mathrm{H}$ NMR titration of thiourea with $\mathrm{Bu}_{4} \mathrm{~N}^{+} \mathrm{Cl}^{-}$in $\mathrm{CDCl}_{3} .{ }^{c}$ Initial rate and ${ }^{d}$ half life of $\mathrm{Cl}^{-}$influx mediated by thiourea (1:250 thiourea to lipid ratio) into vesicles containing lucigenin, as measured by quenching of the fluorescence of lucigenin (see ESI for details). ${ }^{e} \mathrm{EC}_{50}$ (at $270 \mathrm{~s}$ ) from Hill plots to examine the $\mathrm{Cl}^{-} / \mathrm{NO}_{3}{ }^{-}$exchange in vesicles by these transporters as monitored using an ion selective electrode. 
(a)

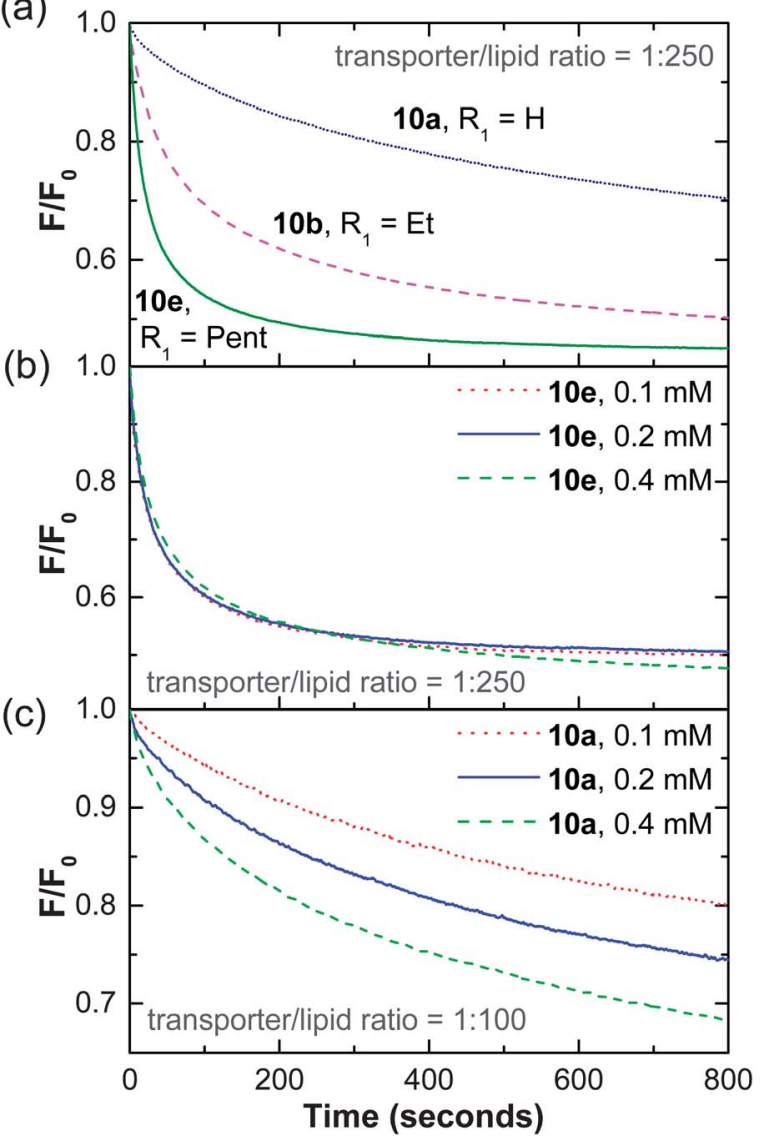

Fig. 3 (a) Chloride transport by thioureas 10a (dotted, dark blue line), $10 \mathrm{~b}$ (dashed, magenta line), and 10e (solid, dark green line) as followed by the lucigenin method. Transporters were preincorporated in vesicles formed from POPC/cholesterol (7:3) at loadings of thiourea : lipid $=1: 250 . F / F_{0}=$ lucigenin fluorescence output relative to starting value. (b) Chloride transport by $10 \mathrm{e}$ (transporter : lipid $=$ $1: 250$ ) after dilution of vesicle suspensions to $0.4 \mathrm{mM}$ (dashed, green), $0.2 \mathrm{mM}$ (solid, blue) and $0.1 \mathrm{mM}$ (dotted, red) total lipid. Traces are almost superimposable, implying that $10 \mathrm{e}$ does not leach from the membrane. (c) Chloride transport by 10a (transporter : lipid =1:100) after dilution of vesicle suspensions to $0.4 \mathrm{mM}$ (dashed, green), $0.2 \mathrm{mM}$ (solid, blue) and $0.1 \mathrm{mM}$ (dotted, red) total lipid. Activities decrease with vesicle concentration, implying that $10 \mathrm{a}$ is lost to the aqueous phase.

concentration-dependent. As shown in Figs. $3 \mathrm{c}$ and $\mathrm{S30}, \dagger$ this is clearly the case for both $\mathbf{1 0 a}$ and $\mathbf{1 0 b}$. For example, at [lipid] = $0.1 \mathrm{mM}, 10 \mathrm{a}$ is less than half as active than at the original concentration of $0.4 \mathrm{mM}$. The differences between 10e, on the one hand, and $\mathbf{1 0 a} / \mathbf{b}$ on the other, provided strong evidence for the validity of this test. They also established that (a) the activity trends in this series are due, at least in part, to differential partitioning between lipid and aqueous phases, and (b) that 10e with $C_{\text {total }}=11$, was essentially confined to the membrane. This value was therefore adopted for the main part of the study.

\section{1-Carbon atom series}

Having established that $C_{\text {total }}$ should be 11, the thioureas 10c, 10d and 10f-h were prepared as further subjects for this study (see ESI $\dagger$ ). Compounds 10c-g provide a sequence in which the thiourea moves from one end of the molecule to the other in steps of 2 or 3 carbons ( $c f$. Fig. 2a), while 10h may be used to probe the effect of the shape of the lipophilic substituent. Representative molecules from this series (10c and $10 \mathrm{~g}$ in addition to 10e) were tested for leaching as described above, with negative results (Fig. S30†). This allowed us to quantify the transport of chloride by these compounds, knowing that all transporter molecules were present in the lipid bilayer phase of the vesicles.

Transport efficiencies for the new thioureas were assayed by the lucigenin method and compared to the results for 10e. Fluorescence decay traces for compounds $10 \mathrm{c}$ and $\mathbf{1 0 g}$ (at either end of the series) are shown in Fig. 4a, alongside that for 10e. It is immediately apparent that the position of the thiourea within the molecule has a very substantial effect; the transporter with a centrally-located anion-binding site is considerably more active than those with peripheral thioureas. Traces for the intermediate compounds 10d and 10f confirm the trend, showing intermediate effectiveness (Fig. S29†). The full set of transport data for 10c-g, quantified both as initial rate $I$ and decay halflife $t_{1 / 2}$, are summarised in Table 1 and presented graphically in Fig. 4 b. By both measures, the central compound 10e is over
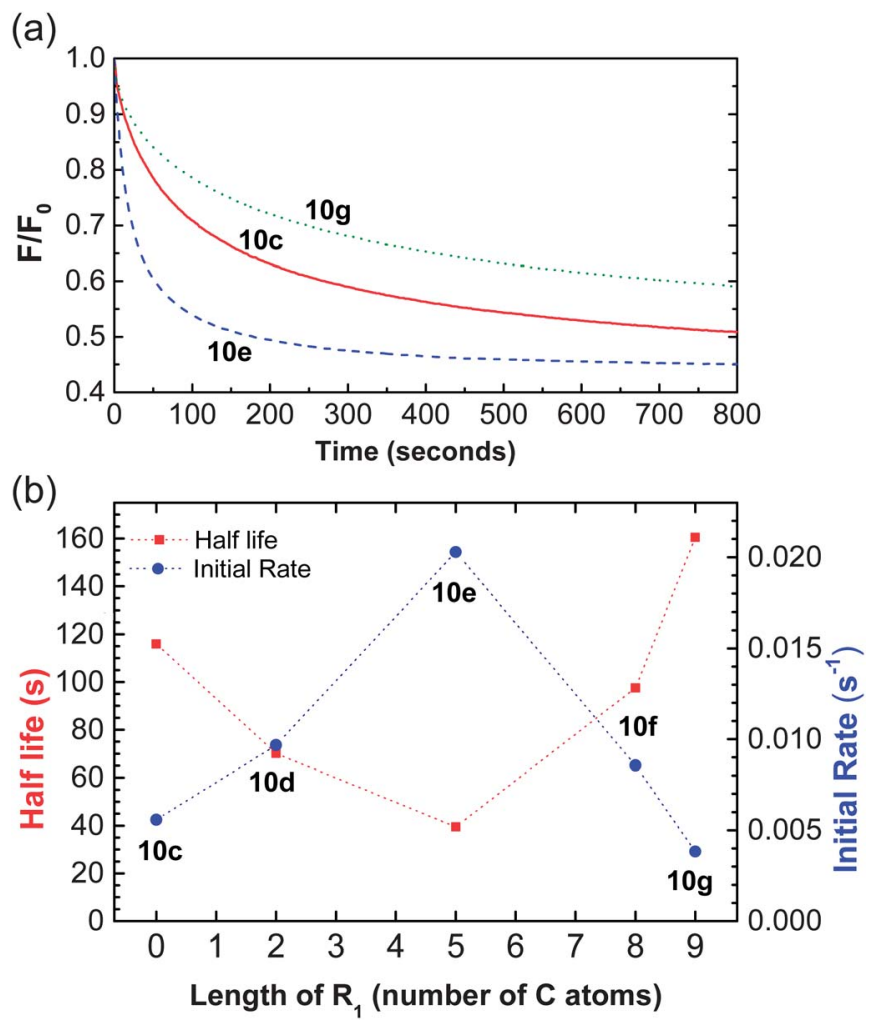

Fig. 4 (a) Chloride transport by thioureas 10c (solid red line), 10e (dashed blue line), and $10 \mathrm{~g}$ (dotted green line) as followed by the lucigenin method. Transporters were preincorporated in vesicles formed from POPC/cholesterol (7:3) at loadings of thiourea : lipid = $1: 250$. (b) Plots of the half life (left axis, red squares) and initial rate values (right axis, blue dots) of chloride transport by thiourea compounds $10 c-g$ as functions of the length of alkyl chain $R_{1}$. Activities peak for $10 \mathrm{e}$ in which the phenylthiourea unit sits close to the centre of the $C_{11}$ chain. 
twice as active as $\mathbf{1 0 d}$ and 10f, around 4 times as effective as 10c and more than 5 times as active as $\mathbf{1 0 g}$.

To attribute this observed trend reliably to the positions of alkyl chains in compounds $\mathbf{1 0 c}-\mathbf{g}$, we had to exclude the effects caused by different binding constants or different overall lipophilicities. We therefore measured these parameters and the results are presented in Table 1 . Binding constants $\left(K_{\mathrm{a}}\right)$ to $\mathrm{Bu}_{4} \mathrm{~N}^{+} \mathrm{Cl}^{-}$in $\mathrm{CDCl}_{3}$ varied little for 10d-g lying between 42 and $53 \mathrm{M}^{-1}$. Not unexpectedly, the affinity shown by 10c was slightly higher at $107 \mathrm{M}^{-1}$; phenyl is more electron-withdrawing than $p$ alkylphenyl, leading to higher $\mathrm{NH}$ acidity. We should note however, that this higher affinity should improve its transport properties so presumably offsets the "position effect" discussed herein. Compound $\mathbf{1 0 c}$ is in fact slightly more active than $\mathbf{1 0 g}$ at the other end of the sequence, but is still one of the two least effective transporters. The lipophilicities of compounds $\mathbf{1 0 c}-\mathbf{g}$, as measured by HPLC, were very similar indeed; retention times all lay between 11.7 and 12 minutes.

As compound 10e gave rise to the fastest transmembrane anion transport, we were also interested to test its analogue $\mathbf{1 0 h}$ in which the linear hexyl chain at $\mathrm{R}_{2}$ was replaced by the more compact and rigid cyclohexyl. The change from linear to cyclic side-chain produced very little effect; compound $\mathbf{1 0 h}$ was marginally less active that 10e, but this could be accounted for by minor decreases in anion affinity and/or lipophilicity (see Table 1 for data).

Finally, anion transport by compounds $\mathbf{1 0 a}-\mathbf{h}$ was also tested by a second procedure involving addition of carrier to preformed vesicles containing chloride, and measurement of $\mathrm{Cl}^{-}$ efflux using an ion exchange electrode (ISE; see ESI for details $\dagger$ ). The results were quantified as $\mathrm{EC}_{50}$ values, i.e. the concentration of transporter (in mole\% with respect to lipid) required to elicit half the maximum observed response in the ISE signal at $t=270$ seconds. As shown in Table 1, the values for compounds 10c-g followed the same pattern, with activity peaking at compound 10e.

\section{Why does lipophilic balance matter?}

The results described above show clearly that the distribution of lipophilicity in anion transporters can have a substantial effect on activity. It seems that the preferred arrangement is to locate the anion-binding site at the centre of the molecule, i.e. with a balanced arrangement of lipophilic groups on either side. It is possible that this effect is due to differences in self-association within the membrane. However, this does not seem likely given that thioureas are not especially prone to aggregation, and that $\mathbf{1 0 c - g}$ are structurally very similar. Instead, we suggest that the role of lipophilic balance is to promote the transition between polar and apolar regions of the membrane bilayer. As shown schematically in Fig. 5, the POPC-based membrane may be divided into (i) the apolar hydrocarbon core and (ii) two polar surface regions dominated by the zwitterionic head-groups, flanked by aqueous phases containing the anionic substrates. Comparing compounds $\mathbf{1 0 g}$ and $\mathbf{1 0 e}$, respectively the least and most active of the series, the former is quite close to a classic surfactant structure with polar head-group and lipophilic tail. If the $N$-ethylurea head-group binds a chloride ion from solution

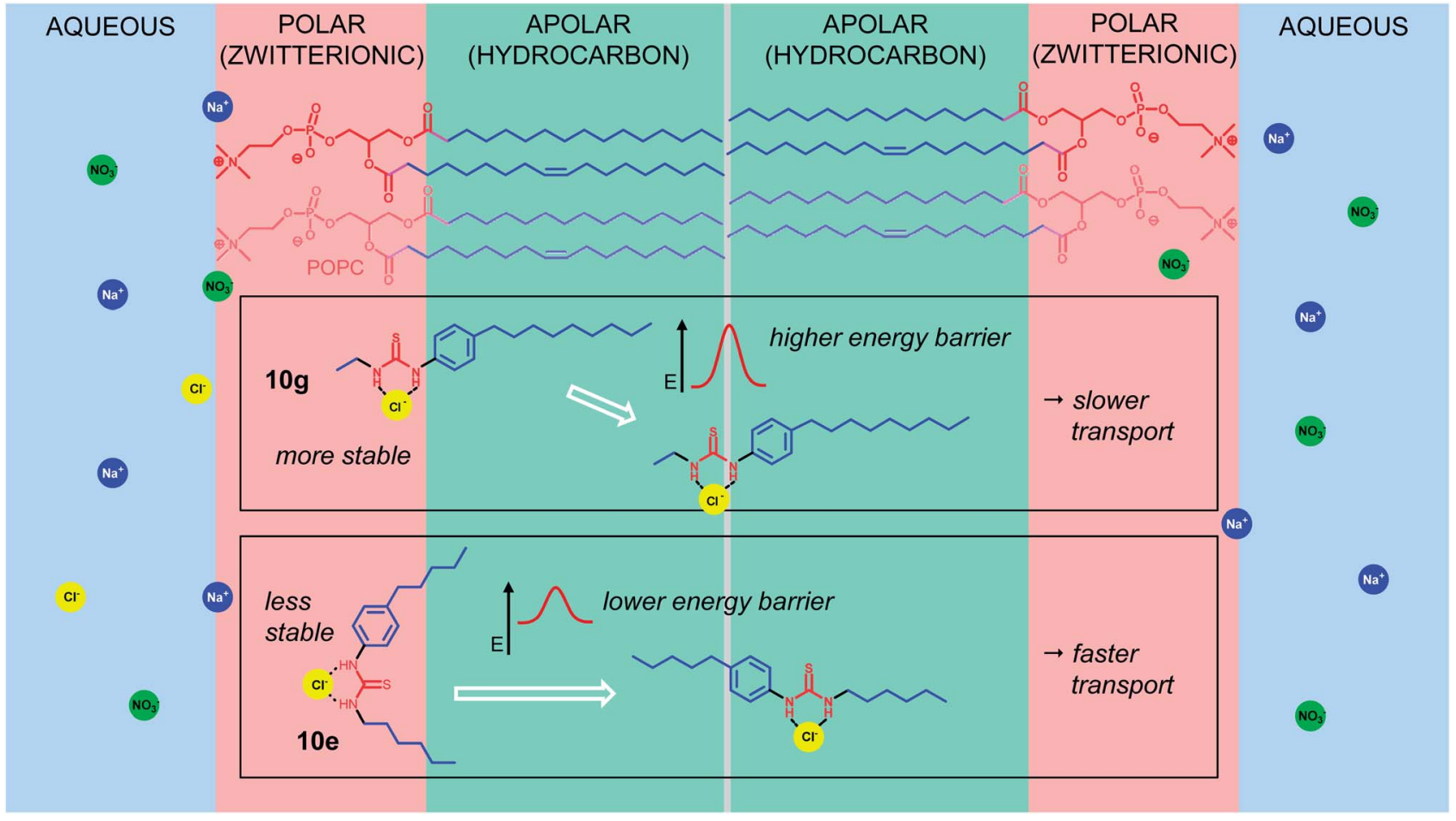

Fig. 5 Rationalising the effect of lipophilic balance on transport activity. Asymmetric transporter $10 \mathrm{~g}$ binds chloride to create a surfactant-like structure which integrates well with the membrane. Motion across the apolar region is thus relatively slow. The more balanced transporter $10 \mathrm{e}$ binds chloride as well as $10 \mathrm{~g}$, but the complex is less comfortable at the interface and more inclined to pass through the membrane interior. 
its polarity is greatly increased, creating a unit which sits comfortably in the hydrated polar region of the membrane. ${ }^{26}$ It is easily imagined that the transition from this environment to the apolar membrane interior could be quite unfavourable. In contrast the binding site of compound 10e, with substantial lipophilic groups on both sides, is less compatible with the polar surface regions. Having bound the target anion it has less incentive to stay in place and is better adapted to shepherd the anion through the membrane interior.

\section{Conclusions}

It has been known for some time that the activity of anion carriers is determined not just by anion affinities and global lipophilicities, but also by other factors. However, until now, these other factors have remained ill-defined. The work described herein points clearly to a new factor or design principle, that of "lipophilic balance". In a series of anionophores with closely similar affinities, sizes and lipophilicities, we have shown that variants with centralised binding sites, and thus a balanced arrangement of lipophilic groups, show greater effectiveness. The scale of the effect is considerable, and might be thought surprising. For example, moving four carbons from one side of the system to the other (as in $10 \mathrm{~g} \rightarrow \mathbf{1 0 e}$ ) can produce a $>5$-fold increase in activity. The results provide further confirmation that binding the target anion from water is only one aspect of anionophore activity, and that crossing the apolar barrier from one interface to the other is not straightforward. In future work we hope to uncover further principles that govern this process and can be used to design anionophores with potential for real-world applications.

\section{Acknowledgements}

This work was supported by the Engineering and Physical Sciences Research Council (grant numbers EP/F03623X/1 and EP/J009687/1) and the European Cooperation in Science and Technology (COST) action CM1005 "Supramolecular Chemistry in Water". PAG thanks the Royal Society and the Wolfson Foundation for a Royal Society Wolfson Research Merit Award.

\section{Notes and references}

1 (a) A. P. Davis, D. N. Sheppard and B. D. Smith, Chem. Soc. Rev., 2007, 36, 348-357; (b) G. W. Gokel and N. Barkey, New J. Chem., 2009, 33, 947-963; (c) J. T. Davis, O. Okunola and R. Quesada, Chem. Soc. Rev., 2010, 39, 3843-3862; (d) S. Matile, A. V. Jentzsch, J. Montenegro and A. Fin, Chem. Soc. Rev., 2011, 40, 2453-2474; (e) N. Busschaert and P. A. Gale, Angew. Chem., Int. Ed., 2013, 52, 1374-1382; $(f)$ H. Valkenier and A. P. Davis, Acc. Chem. Res., 2013, 46, 2898-2909; (g) J. T. Davis, Top. Heterocycl. Chem., 2010, 24, 145-176; (h) P. A. Gale, R. Pérez-Tomás and R. Quesada, Acc. Chem. Res., 2013, 46, 2801-2813.

2 B. C. Pressman, Annu. Rev. Biochem., 1976, 45, 501-530.

3 F. M. Ashcroft, Ion Channels and Disease, Academic Press, London, 2000.
4 J. R. Broughman, L. P. Shank, W. Takeguchi, B. D. Schultz, T. Iwamoto, K. E. Mitchell and J. M. Tomich, Biochemistry, 2002, 41, 7350-7358.

5 (a) P. H. Schlesinger, R. Ferdani, J. Liu, J. Pajewska, R. Pajewski, M. Saito, H. Shabany and G. W. Gokel, J. Am. Chem. Soc., 2002, 124, 1848-1849; (b) V. Sidorov, F. W. Kotch, G. Abdrakhmanova, R. Mizani, J. C. Fettinger and J. T. Davis, J. Am. Chem. Soc., 2002, 124, 2267-2278; (c) N. Sakai, D. Houdebert and S. Matile, Chem.-Eur. J., 2003, 9, 223-232; (d) R. E. Dawson, A. Hennig, D. P. Weimann, D. Emery, V. Ravikumar, J. Montenegro, T. Takeuchi, S. Gabutti, M. Mayor, J. Mareda, C. A. Schalley and S. Matile, Nat. Chem., 2010, 2, 533-538; (e) V. Gorteau, G. Bollot, J. Mareda, A. PerezVelasco and S. Matile, J. Am. Chem. Soc., 2006, 128, 14788-14789; (f) C. R. Yamnitz, S. Negin, I. A. Carasel, R. K. Winter and G. W. Gokel, Chem. Commun., 2010, 46, 2838-2840; (g) X. Li, B. Shen, X. Q. Yao and D. Yang, J. Am. Chem. Soc., 2007, 129, 7264-7265; (h) B. Shen, X. Li, F. Wang, X. Q. Yao and D. Yang, PLoS One, 2012, 7, e34694.

6 (a) B. A. McNally, E. J. O'Neil, A. Nguyen and B. D. Smith, J. Am. Chem. Soc., 2008, 130, 17274-17275; (b) A. Hennig, L. Fischer, G. Guichard and S. Matile, J. Am. Chem. Soc., 2009, 131, 16889-16895.

7 A. V. Koulov, T. N. Lambert, R. Shukla, M. Jain, J. M. Boon, B. D. Smith, H. Y. Li, D. N. Sheppard, J. B. Joos, J. P. Clare and A. P. Davis, Angew. Chem., Int. Ed., 2003, 42, 4931-4933.

8 B. A. McNally, A. V. Koulov, T. N. Lambert, B. D. Smith, J. B. Joos, A. L. Sisson, J. P. Clare, V. Sgarlata, L. W. Judd, G. Magro and A. P. Davis, Chem.-Eur. J., 2008, 14, 9599-9606. 9 (a) N. J. Andrews, C. J. E. Haynes, M. E. Light, S. J. Moore, C. C. Tong, J. T. Davis, W. A. Harrell and P. A. Gale, Chem. Sci., 2011, 2, 256-260; (b) N. Busschaert, P. A. Gale, C. J. E. Haynes, M. E. Light, S. J. Moore, C. C. Tong, J. T. Davis and W. A. Harrell Jr, Chem. Commun., 2010, 46, 6252-6254; (c) N. Busschaert, M. Wenzel, M. E. Light, P. Iglesias-Hernández, R. Pérez-Tomás and P. A. Gale, J. Am. Chem. Soc., 2011, 133, 14136-14148; (d) N. Busschaert, L. E. Karagiannidis, M. Wenzel, C. J. E. Haynes, N. J. Wells, P. G. Young, D. Makuc, J. Plavec, K. A. Jolliffe and P. A. Gale, Chem. Sci., 2014, DOI: 10.1039/C3SC52006D.

10 S. J. Moore, M. Wenzel, M. E. Light, R. Morley, S. J. Bradberry, P. Gomez-Iglesias, V. Soto-Cerrato, R. PerezTomas and P. A. Gale, Chem. Sci., 2012, 3, 2501-2509.

11 N. Busschaert, S. J. Bradberry, M. Wenzel, C. J. E. Haynes, J. R. Hiscock, I. L. Kirby, L. E. Karagiannidis, S. J. Moore, N. J. Wells, J. Herniman, G. J. Langley, P. N. Horton, M. E. Light, I. Marques, P. J. Costa, V. Felix, J. G. Frey and P. A. Gale, Chem. Sci., 2013, 4, 3036-3045.

12 C. J. E. Haynes, N. Busschaert, I. L. Kirby, J. Herniman, M. E. Light, N. J. Wells, I. Marques, V. Felix and P. A. Gale, Org. Biomol. Chem., 2014, 12, 62-72.

13 A. V. Jentzsch, D. Emery, J. Mareda, S. K. Nayak, P. Metrangolo, G. Resnati, N. Sakai and S. Matile, Nat. Commun., 2012, 3, 905. 
14 L. Adriaenssens, C. Estarellas, A. V. Jentzsch, M. M. Belmonte, S. Matile and P. Ballester, J. Am. Chem. Soc., 2013, 135, 8324-8330.

15 C. J. E. Haynes, S. J. Moore, J. R. Hiscock, I. Marques, P. J. Costa, V. Felix and P. A. Gale, Chem. Sci., 2012, 3, 1436-1444.

16 N. Busschaert, I. L. Kirby, S. Young, S. J. Coles, P. N. Horton, M. E. Light and P. A. Gale, Angew. Chem., Int. Ed., 2012, 51, 4426-4430.

17 P. V. Santacroce, J. T. Davis, M. E. Light, P. A. Gale, J. C. Iglesias-Sanchez, P. Prados and R. Quesada, J. Am. Chem. Soc., 2007, 129, 1886-1887.

18 J. T. Davis, P. A. Gale, O. A. Okunola, P. Prados, J. C. IglesiasSanchez, T. Torroba and R. Quesada, Nat. Chem., 2009, 1, 138-144.

19 S. Bahmanjah, N. Zhang and J. T. Davis, Chem. Commun., 2012, 48, 4432-4434.
20 S. J. Moore, C. J. E. Haynes, J. Gonzalez, J. L. Sutton, S. J. Brooks, M. E. Light, J. Herniman, G. J. Langley, V. Soto-Cerrato, R. Perez-Tomas, I. Marques, P. J. Costa, V. Felix and P. A. Gale, Chem. Sci., 2013, 4, 103-117.

21 S. Hussain, P. R. Brotherhood, L. W. Judd and A. P. Davis, J. Am. Chem. Soc., 2011, 133, 1614-1617.

22 B. A. McNally, A. V. Koulov, B. D. Smith, J. B. Joos and A. P. Davis, Chem. Commun., 2005, 1087-1089.

23 V. Saggiomo, S. Otto, I. Marques, V. Felix, T. Torroba and R. Quesada, Chem. Commun., 2012, 48, 5274-5276.

24 L. W. Judd and A. P. Davis, Chem. Commun., 2010, 46, 22272229.

25 In the case of bis-trifluoromethylphenylurea $8 \mathbf{c}(\mathrm{R}=\mathrm{Me})$. 26 A similar arrangement, supported by UV-vis spectra, has been proposed for $N$-alkyl- $N^{\prime}-p$-nitrophenylthioureas in DDAB cationic vesicles. See: T. Hayashita, T. Onodera, R. Kato, S. Nishizawa and N. Teramae, Chem. Commun., 2000, 755-756. 